\title{
Hydatid Cyst in the Anterior Abdominal Wall; A Case Presentation
}

\author{
Naila Jabeen ${ }^{*}$, Qamaruddin Baloch ${ }^{2}$, Anila Rahim², Farhan Zaheer ${ }^{2}$ \\ ${ }^{1}$ Radiology Department, Dow University of Health Sciences, Karachi, Pakistan. \\ ${ }^{2}$ Dow University of Health Sciences, Karachi, Pakistan.
}

\begin{abstract}
Objective: A 30 years old male presented with swelling in right abdomen. Initially it was small but with the passage of time it gradually increased in size. The surgical exploration revealed mass present in anterior abdominal wall without involvement of intra-abdominal structure. CT scan of abdomen was suggestive of intra-abdominal, but surprisingly hydatid cyst was found in anterior abdominal wall without intra abdominal involvement.
\end{abstract}

Keywords: Hydatid cyst, Anterior abdominal wall, Swelling, Echinococcus, Abdomin.

\section{INTRODUCTION}

It is an exceptional entity to have hydatid cyst in abdominal wall, even in those countries where ecchinococcus granulosis infestation is endemic. Hydatid disease is caused by the larval stage of the Echinococcus tapeworn [1-4]. The two major types of hydatid disease are caused by E. granulosus and $E$. multilocularis [5]. Echinococcus granulosis is most commonly seen worldwide which affects humans.

Various studies suggest that liver is involved in approximately $75 \%$ of cases while lung in $15 \%$ of cases. Other anatomical location in $10 \%$ of cases [6] liver is frequently involved organ as it acts as the first line of defense [7].

\section{CASE PRESENTATION}

A 30 years old male presented in the OPD with complaints of gradually increasing pain and swelling in the right iliac fossa for 7 months with the history of contact with dogs and sheep. On examination there were two swellings of about $5 \times 5 \mathrm{~cm}$ each in the right lower quadrant near the midline. Swelling was beneath the rectus muscle. It is mobile in a transverse direction and immobile in the longitudinal direction. Based on the findings, a provisional diagnosis of mesenteric cyst was made and further workup was done (Fig. 1).

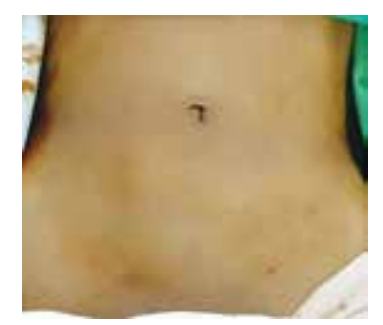

Fig. (1). Showing Swelling Present in the Right Side of Abdomen in the Patient.

\footnotetext{
*Address correspondence to this author at the Radiology Department, Dow University of Health Sciences, Karachi, Pakistan.

E-mail:drnaila.dimt@gmail.com
}

His CBC, Urea, creatinine, PT, INR, electrolytes, HCV and HBV were done which shows HB as $15 \%$, TLC 8.1, Eosinophils count $3 \%$, Platelets 252, PT 11, APTT 22.3, INR 1.05, BUN 12, Creatinine 1.20, Na 145, K 4.2, Cl 97, Bililrubin 0.5, ALT 15 and ALP 65. Anti HCV and HBsAg were both negative.

Ultrasound findings showed two cystic lesions seen in right iliac fossa measuring $7.5 \times 6 \mathrm{~cm}$ and $5.8 \times 5.7 \mathrm{~cm}$. A large bilobed cystic lesion measuring $11.2 \times 4.5 \mathrm{~cm}$ with small cysts in the periphery of large cyst noted below the umbilicus lateral to the midline. On doppler no central vascularity noted. Impression as bilobed benign looking mesenteric cyst was observed.

CT scan findings showed that multiple cystic lesions noted in the pelvis largest $7.6 \times 6.8 \mathrm{~cm}$. It is displacing the adjacent bowel loops and indenting the urinary bladder inferiorly. It is causing pressure effect and indentation of the right rectus muscle (Fig. 2). Impression on CT scan showed that above findings are likely suggestive of hydatid cyst. Other differential could be mesenteric cysts. However echinococcus antibody titer was negative (0.239).

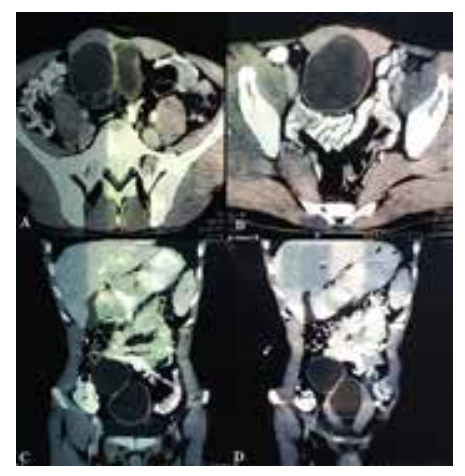

Fig. (2). Showing Contract Enhanced C.T Abdomen and Pelvis Images.

www.njhsciences.com 
With the provisional diagnosis of intra-abdominal hydatid cyst, exploratory laparotomy done by midline incision. Surprisingly there was no intra-abdomical cyst but cystic swelling in the anterior abdominal wall. When rectus sheath was opened two hydatid cyst were found between the posterior rectus sheath and the peritoneum. They contained clear fluid and few daughter cysts. Pericystectomy was performed, and postoperative recovery was uneventful. (Fig. 3 and 4). Patient was put on tab. albendazole $400 \mathrm{mg}$ BD. Midline abdominal wound was closed (Fig. 5).

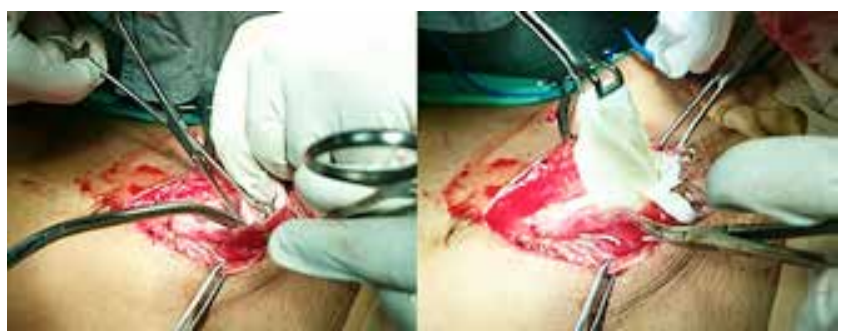

Fig. (3). Showing Midline Incision Being Made.



Fig. (4). Showing Hydatid Cyst Seen in Kidney Tray After Removal.

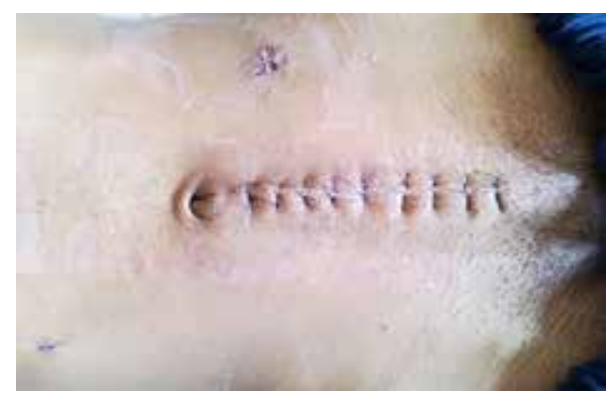

Fig. (5). Showing Abdominal Wall closed.

\section{DISCUSSION}

Hydatid cyst is serious public health problem in endemic area. It is parasitic infection caused by Echinococcus granulosus. Since 2000 years hydatid disease of the liver is known to Hippocrate caused by larva of the dog tapeworm, Echinococcus granulosis, while men are accidental host [8]. It is unique parasitic disease which is found worldwide specially in the Middle East North Africa, South Africa, Australia, New Zealand [9]. The hydatid cyst can occur anywhere in the body.
Various studies suggest that liver is most frequently involved organ $(75 \%)$ followed by lung $(15 \%)$, other organ involved are heart pericardium, orbit, gastric wall, mussels and adrenal glandes [10-13].

The solitary primary location in anterior abdominal wall is an exceptional entity and is incidence is less than $1 \%$. In our patient, the Hydatid cyst was located in anterior abdominal wall without the involvement of any intra-abdominal structure.

It was very unusual presentation we have already discussed, it is common in liver and lung but no structure of body is exempted from involvement of the hydrated cyst. It means the hydrated cyst can occur in any part of the body.

\section{CONCLUSION}

The case we report here is Hydatid cyst in anterior abdominal wall, which is rare entity it was not picked by ultrasound, CT scan, as anterior abdominal wall hydatid cyst. Echinococcus titre was normal. Before operation it was considered as intra-abdominal hydrated cyst but after surgical exploration it was found in anterior abdominal wall without involvement of intra-abdominal structure. There should be high index of suspicion of hydatid cyst of Anterior abdominal wall while dealing with other anterior abdominal wall swellings and it should be kept in differential diagnosis.

\section{CONFLICT OF INTEREST}

Declared none.

\section{ACKNOWLEDGEMENTS}

Declared none.

\section{REFERENCES}

[1] Filippou D, Tselepis D, Filippou G, Papadopoulos V. Advances in liver echinococcosis: diagnosis and treatment. Clin Gastroenterol Hepatol 2007; 5(2): 152-9.

[2] Zippi M, Siliquini F, Fierro A, et al. Diffuse abdominal hydatidosis: role of magnetic resonance imaging. La Clin Ter 2006; 158(3): 231-3.

[3] Amin MU, Mahmood R, Manzoor S, Ahmad S. Hydatid cysts in abdominal wall and ovary in a case of diffuse abdominal hydatidosis: Imaging and pathological correlation. J Radiol Case Rep 2009; 3(5): 25.

[4] Eckert J, Deplazes P. Biological, epidemiological and clinical aspects of echinococcosis, a zoonosis of increasing concern. Clin Microbiol Rev 2004; 17(1): 107-35.

[5] Dinkel A, Njoroge EM, Zimmermann A, et al. A PCR system for detection of species and genotypes of the Echinococcus granulosus-complex, with reference to the epidemiological situation in eastern Africa. Int J Parasitol 2004; 34(5): 645-53. 
[6] Pedrosa I, Saiz A, Arrazola J, Ferreiros J, Pedrosa CS. Hydatid disease: Radiologic and pathologic features and complications. Radiographics 2000; 20: 795-817.

[7] Ramanjulu M, Rao CV, Ananth ML, Nagaraju BN, Naik GR. Hydatid Disease of the Central Nervous System; retrospective study of 20 cases. Indian J Appl Res 2016; 5(10).

[8] Mandal S, Mandal MD. Human cystic echinococcosis: Epidemiologic, zoonotic, clinical, diagnostic and therapeutic aspects. Asian Pacific J Trop Med 2012; 5(4): 253-60.

[9] Romig T. Epidemiology of echinococcosis. Langenbeck's. Arch Surg 2003; 388(4): 209-17.

[10] Ousadden H, Elbouhaddouti K, Ibnmajdoub H, Mazaz K,
AitTaleb K. A solitary primary subcutaneous hydatid cyst in the abdominal wall of a 70-year-old woman: A case report. J Med Case Rep 2011; 5: 270.

[11] Rao NM, Shanthi V, Ramakrishna BA. Anterior abdominal wall hydatid: A rare case report. J Biosci Technol 2011; 2(4): 349-52.

[12] Ozoilo KN, Iya D, Kidmas AT, Uwumarogie O, Hassan S. Anterior abdominal wall hydatid cyst; an unusual presentation. Nigerian J Med 2007; 16(2): 181-2.

[13] Bedioui H, Makni A, Nouira K, et al. Subcutaneous hydatid cyst: Case report of an exceptional location] [in French]. Med Trop (Mars) 2007; 67: 181-2. 